\title{
Insufficient Sedation and Severe Side Effects after Fast Administration of Remifentanil during INSURE in Preterm Newborns
}

\author{
Ellen H.M. de Kort ${ }^{a, c}$ Lidwien M. Hanff ${ }^{b}$ Daniella Roofthooft ${ }^{a} \quad$ Irwin K.M. Reiss ${ }^{a}$ \\ Sinno H.P. Simons ${ }^{a}$

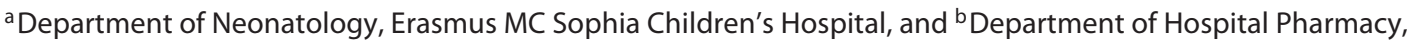 \\ Erasmus MC, Rotterdam, 'Department of Neonatology, Máxima Medical Center, Veldhoven, The Netherlands
}

\section{Key Words}

Remifentanil · Intubation · INSURE · Neonate · Sedation ·

Side effects

\begin{abstract}
Background: Neonatal intubation is stressful and should be performed with premedication. In the case of an INSURE (intubation/surfactant/extubation) procedure a short duration of action of the premedication used is needed to facilitate fast extubation. Given its pharmacological profile, remifentanil seems a suitable candidate. Objectives: The aim here was to evaluate the effect and side effects of remifentanil as a premedication for preterm neonates undergoing INSURE. Methods: A prospective, single-center study in a level III neonatal intensive care unit was conducted. The quality of sedation was assessed in preterm infants receiving remifentanil prior to intubation for the INSURE procedure. Intravenous remifentanil was administered quickly and followed by a saline flush in approximately $30 \mathrm{~s}$. The quality of sedation was defined by a combination of adequate sedation score, good intubation conditions and absence of side effects. Results: The study was terminated after the inclusion of 14 patients because of the high rate of side effects and the poor intuba-
\end{abstract}

\section{KARGER}

(C) 2016 S. Karger AG, Basel

E-Mail karger@karger.com

www.karger.com/neo tion conditions. Adequate sedation was achieved in only 2 patients (14\%). Six patients (43\%) needed additional propofol to obtain adequate sedation. Chest wall rigidity occurred in 6 patients (43\%). Conclusions: The rapid administration of remifentanil provides insufficient sedation and is associated with a high risk of chest wall rigidity in preterm neonates.

(c) 2016 S. Karger AG, Basel

\section{Introduction}

To prevent distress and adverse physiological responses, traumatic damage and failed procedures, neonatal intubation should always be performed with the use of premedication [1-3]. One of the most frequent reasons to intubate neonates is to administer surfactant for respiratory distress syndrome. During the INSURE (intubation, surfactant, extubation) procedure, patients are only briefly intubated for the administration of surfactant and extubated immediately thereafter. To facilitate this rapid extubation, the premedication used should have a rapid onset and very short duration of action.

A recent review on the use of premedication before intubation during the INSURE procedure showed no 
Table 1. Intubation score

\begin{tabular}{lllll}
\hline Item & Score 1 & Score 2 & Score 3 & Score 4 \\
\hline Laryngoscopy & Easy & Fair & Difficult & Impossible \\
Vocal cords & Open & Moving & Closing & Closed \\
Coughing & None & Slight & Moderate & Severe \\
Jaw relaxation & Complete & Slight & Stiff & Rigid \\
Limb movements & None & Slight & Moderate & Severe \\
\hline
\end{tabular}

From Viby-Mogensen et al. [10]

conclusive evidence on the optimal premedication but stated that remifentanil was probably the best candidate because of its unique pharmacological profile [4]. Remifentanil has an extremely brief action, high predictability, rapid onset and offset of action, and immediate recovery of the clinical effect after interruption of the administration [5]. The results of previous studies using remifentanil as single agent were also encouraging [6-8]. We performed an observational prospective study to evaluate the effects and side effects of remifentanil bolus infusion as premedication before the INSURE procedure and report here the results of implementing remifentanil into clinical practice.

\section{Methods}

\section{Study Population}

This prospective study was performed at the level III neonatal intensive care unit of the Erasmus MC Sophia Children's Hospital in Rotterdam, the Netherlands. Before January 2013, surfactant was always administered during a period of conventional ventilation and propofol was used as premedication before intubation. In January 2013 the standard of care was changed to performing the INSURE procedure for the administration of surfactant in all infants with a gestational age $\geq 27$ weeks and birth weight $\geq 750 \mathrm{~g}$. As premedication for the INSURE procedure we started to use remifentanil. Remifentanil was administered intravenously as a fast bolus and followed by an intravenous saline flush in $30 \mathrm{~s}$. After administration, the level of sedation was assessed with a standardized sedation score, performed by rubbing the sole of the patient's foot and judging the motor reaction to that stimulus $(1=$ spontaneous movement; 2 = movement on slight touch; $3=$ movement in reaction to firm stimulus; $4=$ no movement) [9]. In case of inadequate sedation (score 1 or 2), another dose of remifentanil was administered according to the protocol. If sedation was adequate (score 3 or 4 ), the procedure was continued. INSURE procedures were always performed by neonatologists and clinical fellows experienced in neonatal intubations. As soon as the respiratory drive recovered after surfactant administration, the patient was extubated and commenced with nasal continuous positive airway pressure.

Remifentanil in Preterm Newborns

\section{Use of Remifentanil}

Based on the results of the study by Avino et al. [7] and our inexperience with remifentanil, we decided to start with a low dose of $1 \mu \mathrm{g} / \mathrm{kg}$. When sedation was inadequate, this dose could be repeated no more than twice (period 1). If sedation was still inadequate after 3 doses, the patient received propofol $(1 \mathrm{mg} / \mathrm{kg})$ and surfactant was administered in the conventional way. Because sedation was inadequate in 4 of the first 5 patients, the starting dose of remifentanil was increased to $2 \mu \mathrm{g} / \mathrm{kg}$. When sedation was inadequate, another dose of remifentanil was given and each subsequent dose was increased with $1 \mu \mathrm{g} / \mathrm{kg}$ relative to the previous dose with a maximum dose of $5 \mu \mathrm{g} / \mathrm{kg}$ (period 2). If sedation was still insufficient, propofol $(1 \mathrm{mg} / \mathrm{kg})$ was given and surfactant was administered in the conventional way.

\section{Outcome Measures}

The primary outcome measure was the quality of sedation, defined as the combination of an adequate sedation score, adequate intubation conditions and the absence of side effects. Intubation conditions were classified with a validated intubation score by rating laryngoscopy, vocal cords, coughing, jaw relaxation and limb movements (table 1) [10]. Intubation conditions were good when the total score was $\leq 10$ with a score on each item $\leq 2$. Hypotension and chest wall rigidity were defined as side effects. Hypotension was defined as a mean blood pressure lower than gestational age and chest wall rigidity was defined as the inability to inflate with normal pressures. Secondary outcomes were the number of remifentanil doses, maximum remifentanil dose, need for propofol to achieve adequate sedation and intubation attempts.

\section{Ethics Committee Approval}

We received a waiver for ethical approval of the observational trial according to the Dutch Law of Research with Humans (No. 2014.435; Medical Ethical Committee, Erasmus Medical Center, Rotterdam, The Netherlands).

\section{Results}

\section{Characteristics of Included Patients}

Due to insufficient sedation and a high rate of side effects, the use of remifentanil was terminated after the inclusion of 14 patients: 5 patients in study period 1 and 9 
Table 2. Patient characteristics and study outcomes in study periods 1 and 2

\begin{tabular}{|c|c|c|}
\hline & $\begin{array}{l}\text { Study period } 1 \\
(\mathrm{n}=5)\end{array}$ & $\begin{array}{l}\text { Study period } 2 \\
(\mathrm{n}=9)\end{array}$ \\
\hline \multicolumn{3}{|l|}{ Patient characteristics } \\
\hline \multicolumn{3}{|l|}{ Gestational age, weeks } \\
\hline Median & $292 / 7$ & $283 / 7$ \\
\hline Range & $280 / 7$ to $350 / 7$ & $273 / 7$ to $320 / 7$ \\
\hline \multicolumn{3}{|l|}{ Birth weight, $g$} \\
\hline Median & 1,320 & 1,130 \\
\hline Range & $920-2,200$ & $910-1,860$ \\
\hline Gender & 1 male, 4 females & 4 males, 5 females \\
\hline \multicolumn{3}{|c|}{ Primary outcome measures - sedation parameters with remifentanil } \\
\hline Adequate sedation score ( 3 or 4 ) & $2(40)$ & $6(67)$ \\
\hline Adequate intubation score $(\leq 10)$ & $2(40)$ & $4(44)$ \\
\hline Side effects (chest wall rigidity) & 0 & $6(67)$ \\
\hline Adequate sedation & $1(20)$ & $1(11)$ \\
\hline \multicolumn{3}{|l|}{ Secondary outcome measures } \\
\hline \multicolumn{3}{|l|}{ Doses of remifentanil } \\
\hline 1 & $1(20)$ & $2(22)$ \\
\hline 2 & $2(40)$ & $5(56)$ \\
\hline 3 & $1(20)$ & $1(11)$ \\
\hline 4 & $1(20)$ & $1(11)$ \\
\hline Propofol needed & $2(40)$ & $4(44)$ \\
\hline \multicolumn{3}{|l|}{ Intubation attempts } \\
\hline 1 & $2(40)$ & $5(56)$ \\
\hline 2 & $2(40)$ & $3(33)$ \\
\hline 3 & $1(20)$ & 0 \\
\hline Not reported & 0 & $1(11)$ \\
\hline
\end{tabular}

patients in study period 2. The baseline characteristics of the study patients and outcomes in study period 1 and study period 2 are reported in table 2 .

\section{Primary Outcome Measures}

Adequate sedation was by the combination of $3 \mathrm{key}$ components: adequate sedation score, adequate intubation conditions and the absence of side effects. This was achieved in only 2 patients (14\%) of our total study population. In study period 1, 2 patients had an adequate sedation score but 1 of them had inadequate intubation conditions despite this score. In the remaining 3 patients the sedation score was inadequate. Two of them were intubated with propofol while the other was intubated despite the inadequate sedation score. None of the patients developed chest wall rigidity. In summary, adequate sedation based on the 3 key components was only achieved in 1 patient in study period 1 . In study period 2 adequate se- dation scores after remifentanil were achieved in 6 patients. However, only 1 patient also had adequate intubation conditions and no side effects. One patient had inadequate intubation conditions and 4 patients developed chest wall rigidity. In 2 of these latter patients intubation failed or was never tried and propofol was administered. The sedation score was inadequate in 3 patients. In 2 of these patients propofol was used and 1 patient was intubated despite an inadequate sedation score. Two of these 3 patients developed chest wall rigidity. In summary, in study period 2 adequate sedation based on the 3 key components was also only achieved in 1 patient.

Chest wall rigidity was a frequently reported side effect, occurring in 6 patients (43\%), all in study period 2 (67\% of patients in study period 2 ). Chest wall rigidity always occurred directly after the administration of remifentanil and never after the administration of propofol. No other side effects such as hypotension were identified. 


\section{Secondary Outcome Measures}

Overall, 6 patients (43\%) needed propofol to reach adequate sedation. In the 8 patients that achieved an adequate sedation score with only remifentanil, $3(38 \%)$ needed 1 dose, 4 (50\%) received 2 doses and 1 (12\%) received 4 doses. The maximum dose was $1 \mu \mathrm{g} / \mathrm{kg}$ in $3 \mathrm{pa}-$ tients (38\%), $2 \mu \mathrm{g} / \mathrm{kg}$ in 2 patients $(25 \%)$ and $3 \mu \mathrm{g} / \mathrm{kg}$ in 3 patients (38\%). Table 2 displays the number of remifentanil doses in both study periods. Overall, intubation was successful at the first attempt in $54 \%$ of patients, $38 \%$ of patients required a second and $8 \%$ a third attempt. Four intubation attempts failed due to inadequate sedation.

\section{Discussion}

We aimed to evaluate the effectiveness of remifentanil premedication for the INSURE procedure in preterm neonates. However, the results of our observational study show that low doses $(1 \mu \mathrm{g} / \mathrm{kg})$ did not provide adequate sedation and rapidly administered remifentanil resulted in an unacceptable high incidence of chest wall rigidity following a high dose. Based on these results we conclude that remifentanil bolus infusion in $30 \mathrm{~s}$ is not suitable as a premedication for neonatal intubation.

Remifentanil as the single premedication drug has been investigated in 3 previous studies. Welzing et al. [6] studied $2 \mu \mathrm{g} / \mathrm{kg}$ of remifentanil administered over $60 \mathrm{~s}$ in preterm infants undergoing the INSURE procedure. A single dose provided adequate sedation in $81 \%$ of the patients, with $19 \%$ needing a second dose and none of the patients requiring additional medication. Intubation was successful at the first attempt in $71 \%$ of the patients, insufficient sedation was never the reason for a second attempt and intubation conditions were excellent or good in all patients. No chest wall rigidity was reported. Avino et al. [7] administered $1 \mu \mathrm{g} / \mathrm{kg}$ of remifentanil over $60 \mathrm{~s}$ to 36 preterm infants needing (semi)elective intubation and reported similar results to the previous study. Intubation was successful at the first attempt in $75 \%$ of the patients but poor intubation conditions occurred in $24 \%$ of the intubation attempts. Chest wall rigidity occurred in 2 patients (6\%). Choong et al. [8] also investigated remifentanil in elective intubation in neonates at a dose of $3 \mu \mathrm{g} / \mathrm{kg}$ administered over $60 \mathrm{~s}$. They found less positive results, with additional medication needed in $26.7 \%$ of patients, failed first attempts in $60 \%$ of patients, and excellent or good intubation conditions in only $53.6 \%$ of patients. Chest wall rigidity was observed in $13 \%$ of the patients. In our study, remifentanil was found to provide sufficient sedation in only a small number of patients. An explanation may be the faster infusion rate used in our study. Fast infusion is related to higher peak levels, and as a consequence increased side effects and shorter duration of effective sedation [6, 11]. The window of opportunity might have been too short to obtain an adequate sedation score and intubation procedure. We also found a significantly higher incidence of chest wall rigidity, most likely also attributable to the faster infusion rate of $30 \mathrm{~s}$. In retrospect, the chosen duration of infusion was too fast in our study. We used an infusion rate of $30 \mathrm{~s}$ to flush the small volume of remifentanil because this is the standard way to administer many semiacute cardiorespiratory drugs in our intensive care. The results of the current study underline the danger of such a routine way to administer drugs. Based on our results, this is obviously not appropriate and represents important knowledge for other clinicians and researchers who intend to use remifentanil in preterm neonates.

Our study has several limitations, including the small number of patients, no control group treated with another sedative such as propofol, no blinding of doses and no pharmacokinetic analyses of remifentanil. However, our results are an important illustration of daily neonatal care. The combination of opioids with a hypnotic or sedative agent might be more appropriate than the use of a single agent. A slower infusion of remifentanil combined with a low dose of propofol might by an interesting combination to investigate in future studies.

\section{Conclusion}

We conclude that remifentanil boluses administered in $30 \mathrm{~s}$ carry an unacceptably high risk of chest wall rigidity in preterm neonates. Lower doses also provide insufficient sedation.

\section{Disclosure Statement}

All authors have no conflicts of interest to declare. 


\section{References}

1 Sarkar S, Schumacher RE, Baumgart S, Donn SM: Are newborns receiving premedication before elective intubation? J Perinatol 2006; 26:286-289.

2 Oei J, Hari R, Butha T, Lui K: Facilitation of neonatal nasotracheal intubation with premedication: a randomized controlled trial. J Paediatr Child Health 2002;38:146-150.

3 Carbajal R, Eble B, Anand KJS: Premedication for tracheal intubation in neonates: confusion or controversy. Semin Perinatol 2007;31:309_ 317.

4 De Kort EHM, Reiss KMR, Simons SHP: Sedation of newborn infants for the INSURE procedure, are we sure? Biomed Res Int 2013; 2013:892974.
5 Welzing L, Roth B: Experience with remifentanil in neonates and infants. Drugs 2006;66: 1339-1350.

6 Welzing L, Kribs A, Huenseler C, Eifinger F, Mehler K, Roth B: Remifentanil for INSURE in preterm infants: a pilot study for evaluation of efficacy and safety aspects. Acta Paediatr 2009;98:1416-1420.

7 Avino D, Zhang WH, De Ville A, Johansson $\mathrm{AB}$ : Remifentanil versus morphine-midazolam premedication on the quality of endotracheal intubation in neonates: a non-inferiority randomized trial. J Pediatr 2014;164:10321037.

8 Choong K, Alfaleh K, Doucette J, Gray S, Rich B, Verhey L, Paes B: Remifentanil for endotracheal intubation in neonates: a randomised controlled trial. Arch Dis Child Fetal Neonatal Ed 2010;95:F80-F84.
9 Naulaers G, Deloof E, Vanhole C, Kola E, Devlieger A: Use of methohexital for elective intubation in neonates. Arch Dis Child Fetal Neonatal Ed 1997;77:F61-F64.

10 Viby-Mogensen J, Engbaek J, Eriksson LI, Gramstad L, Jensen E, Jensen FS, KoscielniakNielsen Z, Skovgaard LT, Ostergaard D: Good clinical research practice (GCRP) in pharmacodynamic studies of neuromuscular blocking agents. Acta Anaesthesiol Scand 1996;40: 59-74.

11 Simons SH, van Dijk M, Tibboel D: Remifentanil to relieve pain associated with peripherally inserted catheters in preterm infants: the new way to go? Pediatr Crit Care Med 2014;15:495-497. 